\title{
Impact of Coronavirus Pandemic on the Psychological State and Academic Success of Students
}

\author{
NDUKWU Edith $N^{1}$, NDUKWU Eric Chima ${ }^{2 *}$ and IGBO Janet $N^{2}$ \\ ${ }^{1}$ Department of Social Science Education, University of Nigeria Nsukka, Nigeria \\ ${ }^{2}$ Department of Educational Foundations, University of Nigeria Nsukka, Nigeria
}

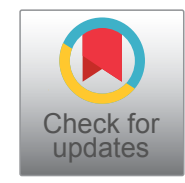

\begin{abstract}
This study examines the effect of Coronavirus pandemic on psychological state of students in south-Eastern Nigeria. Three research questions and three null hypotheses were formulated to guide the study. Ex-post facto research design was adopted to study a sample of 303 University students who accepted to be part of this study. One trial tested instrument with three clusters, covering; depression, anxiety and academic success was used for data collection. Data obtained with the instrument were analyzed using mean, standard deviation and t-test. The findings revealed that Coronavirus pandemic has caused anxiety and depression to many students. It was also found that Covid-19 has a devastating effect on the psychological state and academic success of students. It was also discovered that Covid-19 has slightly different effect on males and females. Among other things, the educational implication of this study is that, psychological state is essential for academic success. It was recommended that Coronavirus pandemic should be dealt with so that students can focus on their study without anxiety and depression.
\end{abstract}

\section{Keywords}

Academic success, Anxiety, Coronavirus pandemic, Depression, Psychological state

\section{Introduction}

The recent outbreak of hydra headed monster called Coronavirus (COVID-19) pandemic has shook the whole world and trigger anxiety and depression in all corners of the globe. The rate at which the pandemic is annihilating people in many parts of the world $r$ has affected students' psychological state, academic success and has also caused death anxiety and depression among both students and non students.

COVID-19 which originated in Wuhan in China and was reported to the world health organization on the $31^{\text {st }}$ of December 2019 has ravaged the whole world like a wild fire. COVID-19 is the infectious disease caused by the most recently discovered coronavirus. Coronavirus disease (COVID-19) is an infectious disease caused by a newly discovered coronavirus [1].

A lot of myths have surrounded the remote cause of the ailment. Whether the stories about the main cause of Coronavirus pandemic are true of false is inconsequential but the truth is that the pandemic has ravaged many aspects of human life in America and Europe than in Africa, especially Nigeria.

\section{Nigeria and COVID-19 pandemic}

The government of the federal republic of Nigeria introduced a lockdown, prohibiting markets, worship centers, social gatherings, wedding ceremonies, burials, intra and international movements like many countries of the world did. Many business men and women in Nigeria were bankrupt because they lost all their business capital during the several months of lockdown. The lockdown made the prices of available goods and services to skyrocket by $1,200 \%$.

Many state governments in Nigeria also introduced more stringent measures to wage war against the alleged spread of COVID-19, not minding that a lot of Nigerians depend on daily pay. Such heinous leaders did not provide food or care about the outcries of Nigerians from different quarters of the country that the lockdown was creating an obnoxious situation, called hunger crisis. This new development affected a lot of people, especially students who faced a lot challenges during the first wave of Coronavirus pandemic. These challenges range from hunger, to anxiety, depression and frustration.

*Corresponding author: NDUKWU, Eric Chima, Department of Educational Foundations, University of Nigeria Nsukka, Nigeria, Tel: 07036866966

Accepted: June 12, 2021

Published online: June 14, 2021

Citation: Edith NN, Eric NC, Janet IN (2021) Impact of Coronavirus Pandemic on the Psychological State and Academic Success of Students. J Depress Anxiety Disord 3(1):82-88 
During the first wave of COVID-19 in Nigeria, corruption manifested prominently in the distribution of the few palliatives and social amenities share to a negligible number of the population. Very few people received the palliatives, but the government of the federal republic of Nigeria announced that Nigerians are not hungry; everybody has received palliatives. Many Nigerian families were dying of hunger and needed practical help which includes; money, food, water, sanitizers, face masks and healthcare to survive the dark period of the COVID-19 pandemic. Many people died in Nigeria during the Coronavirus pandemic severe lockdown due to hunger and not the ailment. The poor masses in Nigeria were languishing in penury while the state governors were busy looting the funds provided by international organizations to reduce hunger and suffering among Nigerians.

The saddest of it all was that, instead of the rich businessmen, church general overseers, bank chief executive officers and oil barons in Nigeria to help the poor masses with palliatives, they donated billions of Naira to the federal and state governments which did not care about the wellbeing of the poor people. Recently it was on the national news in Nigeria that the whole money donated to solve the problem of COVID-19 caught fire and burnt to ashes. That news left many Nigerians depressed and frustrated, especially students who were hopeful that the donations would help the government to solve the problems posed by COVID-19 and schools will reopen, and they go back to school again.

The government of the federal republic of Nigeria is claiming that many thousands people have contracted the virus and that a lot of people have died from the virus, but till now nobody has seen the dead bodies of those who died from COVID-19 except that of Mr. Abba Kari the former chief of staff to Buhari, the president of Nigeria who was alleged to have been killed by COVID-19. Nigerians are yet to see and know the hospitals where the COVID-19 victims are being treated, the prescribed treatment for COVID-19 victims in Nigeria and where the dead victims were buried. Yet those in authority are claiming that they are treating and discharging recovered COVID-19 victims. It was later gathered that the acclaimed COVID-19 victims were actually suffering from malaria, not COVID-19. But the health authorities in Nigeria continue to cook and inflate data by claiming that who so ever comes to the hospital for any treatment was suffering from COVID-19. In America and Europe, everyone sees the hospitals where COVID-19 victims are treated, the dead bodies of COVID-19 victims and where they are buried.

Nigerian authorities claim to have constructed isolation centers for COVID-19 victims, but the truth is that the few constructed isolation centers in Nigeria are empty; that is without patients. But despite the fact that most Nigerians believe that the COVID-19 figures in Nigeria seems to be fabricated, exaggerated and unrealistic, many Nigerian students are currently suffering from anxiety and depression as they are uncertain about their future now that the world COVID-19 cases are in millions, with hundreds of thousand deaths. Nigerian schools are closed indefinitely so that students will not contract COVID-19 victims. But the irony in the fight against COVID-19 in Nigeria is that political
Rallies, gubernatorial, local government elections are holding and people do not contract COVID-19 in such gatherings according to the Nigerian Government and the Nigeria Centre for Disease Control (NCDC). The question is who is cheating who? That is the reason why many Nigerians don't believe that there is COVID-19 in Nigeria is because what we have is malaria, the symptoms diagnosed from supposed COVID-19 victims in Nigeria is of malaria, not COVID-19.

\section{COVID-19 anxiety and depression in Nigerian students}

Many Nigerians were frustrated with the manner of corruption, lies; deceptions and pranks politicians played with COVID-19 pandemic in Nigeria during the first wave. Many Nigerians are worried and horrified with the recent news of the second wave of COVID-19 pandemic. Today, Nigerian students are depression due to fear of uncertainties. They don't know whether they will survive this perilous COVID-19 period alive, not because of the illness but because of the hardship associated with the period. In Nigeria, many families have looked themselves in doors for many months to avoid the dreaded COVID-19. Such people are depressed because they are gripped by death anxiety. Death is anxiety caused by thoughts of death. Predatory death anxiety arises from the fear of being harmed [2]. This kind of anxiety suffered by Nigerian students today is due to the hardship they face due to COVID-19, it is different from Existential death anxiety which stems from the basic knowledge that human life must end [3].

The corruption, lies and deceptions of government at all levels cumulate to cause anxiety and depression to many Nigerian students who do not know when they will resume schooling again or not. And even if schools reopen now, their parents do not have money to feed them let alone sending them back to school. The Nigerian government gave an ultimatum that all federal Universities in the country must reopen all academic activities on the $18^{\text {th }}$ of January 2021. This ultimatum rekindled a fresh anxiety in undergraduates because most parents have no money to give to their school children, and when they did and the undergraduates returned to school, their respective schools gave the students only two weeks to prepare for exams. The reason behind the ultimatum is to correct and complete the academic calendar destroyed by COVID-19. Nigerian students are anxious now because they know that they may not do well in the exams due to insufficient time for preparation. The remote cause of students' anxiety in Nigeria today is COVID-19. The fear of the unknown called "Anxiety" has led many Nigerians and students to depression.

The depression caused by COVID-19 pandemic in Nigeria has a damaging effect of on Nigerian students. Depression is a mood disorder that involves persistent feelings of sadness, loneliness, hopelessness, and loss of interest in previously enjoyable activities. People experiencing depressive episodes may also experience mood swings, sleep disturbances, appetite changes, and headaches and body pains that have no apparent physical cause. ACHA's 2018 survey indicated that $40 \%$ of American college students experienced at least one 
major depressive episode that year. Symptoms for depression differ from person to person. Ultimately, depression is a result of a chemical imbalance in our brains. The way one person displays signs of depression is not necessarily the way symptoms emerge in others. According to the American Psychological Association, symptoms of depression may include; Physical Well-being Symptoms, Emotional Symptoms and Thinking Symptoms, Changes in sleep habits and appetite changes [4]. Identifying these issues is critical, as students often downplay or simply never talk about things deeply bothering them.

Since March 2020 when students were compelled to vacate from school during the first wave of COVID-19 pandemic, many university undergraduates especially those in the final year classes have become so frustrated and depressed, such that many of them have lost interest in continuing their education. Public universities in Nigeria have reopened but those students who lost interest in education as a result of the distortion caused by COVID-19 have refused to return. Many of them have taken to drugs, gambling, alcoholism and other illicit businesses. They now believe that schooling is a waste of time. All these were caused by COVID-19. Poor psychological state like depression and anxiety cannot support a positive academic success.

Academic success: Academic success could also be called high academic achievement. Academic success means hitting the target people set for themselves, or beating the standards people set for a person or student. In a specific task like a test, it would mean attaining a score that is above average. Academic success could be defined as achieving excellence in all academic disciplines, in class, as well as extracurricular activities, like sporting, behaviour, confidence, communication skills, punctuality, Arts, and Culture [5]. Currently, COVID-19 has hindered both classroom and extracurricular activities and the road to academic success is bleak.

Today's students are psychologically depressed due to pressure from COVID-19 pandemic. Both teachers and students now wear face masks in the classroom, this new development makes teaching and learning difficult, as many classrooms have no public address system. Wearing masks in the classroom makes teaching and learning boring and uninteresting. This is most likely to affect students' future academic success, because only a stable mind can make intellectual exploit. A sound psychological state helps students to plan ahead for tests and assignments. It enables learners to organize their work so that they can avoid being attacked by higher academic requirements than they can afford at the time of reckoning, and to circumvent last minute panic. Philip Zimbardo an American Psychologist said that academic success depends on hard work and preparation, and only a stable mind can make preparations. The COVID-19 Pandemic seems to have a devastating effect on the psychological state of Nigerian Students and their future academic success. This study seeks to determine the effect of Coronavirus pandemic on students' psychological state and academic success.

\section{Research questions} study;
1. What is the effect of Coronavirus pandemic on students' psychological state?

2. What is the effect of Coronavirus pandemic on students' academic success?

3. What is the influence of Coronavirus pandemic on students' psychological state and future academic success based on gender?

\section{Research design}

This study adopted ex-post-facto research design to determine the effect of Coronavirus pandemic on students' psychological state and Academic Success. Ex-post-facto study is that in which the independent variable is not manipulated. The design is appropriate for the study because no variable was manipulated in this study. Ex-post-facto or causal-comparative design helps us to establish a relationship between two or more variables [6]. Ex-post-facto research design can only be used to examine the influence of the independent variable on the dependent variables.

\section{Area of the study}

The area of this study is south East Nigeria comprising of Abia State, Anambra State, Ebonyi State, Enugu State and Imo State. The five states named above claim to have cases of COVID-19 pandemic and have suffered severe tension in Nigeria during this time Coronavirus pandemic was ravaging Africa and the world. The people of the area who are predominantly business oriented have suffered in this period as the can no longer move their goods due to national, inter and intra state lockdown imposed by government of the day.

\section{Sample and sampling technique}

The sample for the study is 303 (150 males and 153 females) university undergraduates from the five who accepted to partake in the study formed the respondents.

\section{Instrument for data collection}

The researcher adapted DASS-21 on Depression, Anxiety, and Stress scale modified by Xinqiao Liu, Siqing Ping, and Wenjuan Gao [7] and used it to measure the psychological state of the respondents. In our study, students' psychological state was assessed using the Depression Anxiety Stress Scales-21 (DASS-21), a self-report measure of the severity of three related negative emotional states. The DASS- 21 has been widely recognized for its reliability and different forms of validity in a range of studies from different countries with different samples. Each of the three DASS-21 scales is measured with seven items. Specifically, "the depression scale assesses the state of dysphoria, hopelessness, devaluation of life, self-deprecation, lack of interest/involvement, anhedonia and inertia; the anxiety scale assesses autonomic arousal, skeletal muscle effects, situational anxiety, and subjective experience of anxious affect; the stress scale is sensitive to levels of chronic non-specific arousal, and it assesses difficulty relaxing, nervous arousal, and being easily upset/agitated, irritable/over-reactive and impatient" Scores for depression, anxiety, and stress are calculated by summing the scores of corresponding items, which represent the degrees of 
depression, anxiety, and stress of the subject. It should also be noted that DASS-21 is a short version derived from the basic DASS questionnaire.

\section{Validation of the instrument}

DASS-21 on Depression, Anxiety, and Stress scale modified by Xinqiao Liu, Siqing Ping, and Wenjuan Gao was validated by experts in educational psychology and measurement and evaluation. The comments of the experts were used to structure the instruments for the study [7].

\section{Method of data collection}

The instrument was administered to the respondents by the researchers with the help of twenty (20) research assistants, four (4) in each state to facilitate the study. The research assistants were instructed to collect the instruments back from the respondents the same day, when they must have filled in their opinions in the questionnaires. This is to avoid losses.

Method of data analyses: The data collected by administering the research instrument were organized in tables and analyzed using mean and standard deviations in answering the research questions posed by the researchers to guide the study. A rating scale of 0-5.0 will be used in measuring the degree of severity of depression, anxiety and expected future academic success of respondents. A mean of 2.5-3.0 was used as the yardstick for normal, low or high scores of depression, anxiety, and expected future academic success. Any item having a mean score between 0-2.4 was seen to have a low degree of severity; any item producing a mean score that is between 2.5-3.0 was seen to have a normal degree of severity, while any item generating a mean score that is between 3.1-5.0 was seen to have a high degree of severity. The three null hypotheses were tested at 0.05 level of significance using t-test.

\section{Results}

The data presented this section are in tables and they are in accordance with the scale/instrument, research questions and hypotheses formulated to guide the study.

Table 1 above shows the range and yardstick for measuring students' depression, anxiety, and expected future academic success. It guides our benchmark as regards what determines low, normal and high depression, anxiety, and expected future academic success.

Table 2 shows the item by item descriptive statistical analyses of students' responses on their psychological state (depression, anxiety) and expected future success using

Table 1: Severity labels of depression, anxiety, and expected future academic success.

\begin{tabular}{|l|l|l|l|}
\hline $\begin{array}{l}\text { Degree of } \\
\text { severity }\end{array}$ & Depression & Anxiety & $\begin{array}{l}\text { Future } \\
\text { academic } \\
\text { success }\end{array}$ \\
\hline Low & $0-2.4$ & $0-2.4$ & $0-2.4$ \\
\hline Normal & $2.5-3.0$ & $2.5-3.0$ & $2.5-3.0$ \\
\hline High & $3.1-5.0$ & $3.1-5.0$ & $3.1-5.0$ \\
\hline
\end{tabular}

mean and standard deviation. The table shows the raw scores of students' responses as shown in the table above. The table shows that most of the respondents are anxious and depressed. The table also shows that the respondents have low expectation for future academic success but demonstrate high anxiety and depression over their future academic success.

Data in Table 3 show the mean ratings and standard deviation of students on Psychological State and academic success based on age of those who suffer Coronavirus Psychological State. The table indicates a mean Psychological State difference between students in the following age bracket: 18-22 and 23-27 years in favour of those within the ages of 18-22.

A corresponding hypothesis was raised to further address the research question:

$\mathbf{H}_{01}$ : Coronavirus pandemic has no significant effect on students' psychological state.

The data in indicated by the calculated t-value of 0.401 in respect of psychological state which is significant at 0.581 probability level and therefore significant at 0.05 levels of significance. Thus, the null hypothesis of no significant mean psychological state based on Coronavirus pandemic is not upheld.

Another hypothesis was raised to further address the research question:

$\mathbf{H}_{\mathbf{0 2}}$ : Coronavirus pandemic has no significant effect on students' future academic success.

A t-test result of Coronavirus pandemic on students' future academic success. The data in the table indicate a t-test score of 0.662 . It indicated by the calculated t-value of 0.662 in respect of students' expected future academic success which is significant at 0.000 probability level and therefore significant at 0.05 levels of significance. Thus, the null hypothesis that states that Coronavirus pandemic has no significant influence on students' future academic success is not upheld.

Data in Table 4 indicate that Coronavirus pandemic has significant influence on students' psychological state and expected future academic success based on gender. The data indicate a mean students' psychological state and expected future academic success. The table also revealed a mean psychological state and expected future academic success between males and females in favour of males. This means that males have a slightly better psychological state and hope for a future academic success more than their female counterparts.

A third hypothesis was raised to further address the research question:

$\mathbf{H}_{03}$ : Coronavirus pandemic has no influence on students' psychological state and future academic success based on their gender.

The t-test result of Coronavirus pandemic on students' expected future academic success. The data analyzed indicate 
Citation: Edith NN, Eric NC, Janet IN (2021) Impact of Coronavirus Pandemic on the Psychological State and Academic Success of Students. J Depress Anxiety Disord 3(1):82-88

Table 2: Descriptive statistics of each item in the Depression, Anxiety and Future academic Success Expectation Scales-21 (DASS-21) (modified).

\begin{tabular}{|c|c|c|c|c|c|}
\hline \multirow{2}{*}{ Scale } & \multirow{2}{*}{ Item } & \multicolumn{2}{|c|}{ Male } & \multicolumn{2}{|c|}{ Female } \\
\hline & & Mean & SD & Mean & SD \\
\hline \multicolumn{6}{|c|}{ Depression } \\
\hline & I couldn't seem to experience any positive feeling at all & 4.37 & 0.81 & 3.51 & 0.690 \\
\hline & I found it difficult to work up the initiative to do things & 3.52 & 0.79 & 3.43 & 0.70 \\
\hline & I felt that I had nothing to look forward to & 4.01 & 0.77 & 4.11 & 0.73 \\
\hline & I felt down-hearted and blue & 3.76 & 0.73 & 3.82 & 0.69 \\
\hline & I was unable to become enthusiastic about anything & 3.47 & 0.70 & 3.19 & 0.64 \\
\hline & I felt I wasn't worth much as a person & 3.88 & 0.90 & 3.10 & 0.72 \\
\hline & I felt that life was meaningless & 3.08 & 0.58 & 3.77 & 0.57 \\
\hline \multicolumn{6}{|c|}{ Anxiety } \\
\hline & I was aware of dryness of my mouth & 3.31 & 0.71 & 3.41 & 0.67 \\
\hline & I experienced breathing difficulty & 3.22 & 0.56 & 3.44 & 0.61 \\
\hline & I experienced trembling & 4.00 & 0.60 & 3.20 & 0.76 \\
\hline & $\begin{array}{l}\text { I was worried about situations in which I might panic and make a } \\
\text { fool of myself }\end{array}$ & 3.21 & 0.78 & 4.32 & 0.74 \\
\hline & I felt I was close to panic & 3.12 & 0.75 & 3.33 & 0.69 \\
\hline & $\begin{array}{l}\text { I was aware of the action of my heart in the absence of physical } \\
\text { exertion }\end{array}$ & 3.26 & 0.71 & 3.70 & 0.67 \\
\hline & I felt scared without any good reason & 3.22 & 0.83 & 3.62 & 0.65 \\
\hline \multicolumn{6}{|c|}{ Expected Future Academic Success } \\
\hline & I have hope that I will graduate with an excellent grade & 1.88 & 0.28 & 2.50 & 0.32 \\
\hline & I have hope that the future is bright & 2.31 & 0.31 & 2.62 & 0.39 \\
\hline & I am not sure that I will graduate & 4.44 & 0.52 & 3.65 & 0.48 \\
\hline & I can no longer concentrate and read my books & 4.77 & 0.50 & 3.93 & 0.41 \\
\hline & I have forgotten all I was taught in school. & 3.39 & 0.46 & 3.15 & 0.46 \\
\hline & I can no longer trust my ability to do well in school & 4.37 & 0.54 & 3.51 & 0.69 \\
\hline & I feel like leaving school now & 2.93 & 0.33 & 3.11 & 0.49 \\
\hline
\end{tabular}

Table 3: A Mean ratings and Standard Deviation on the effect of Coronavirus Pandemic on Students' Psychological State and Academic Success based on age.

\begin{tabular}{|c|c|c|c|c|}
\hline Coronavirus pandemic & $\mathbf{N}$ & Mean & $\begin{array}{l}\text { Std. } \\
\text { Deviation }\end{array}$ & $\begin{array}{l}\text { Mean } \\
\text { Difference }\end{array}$ \\
\hline \multicolumn{5}{|c|}{ Psychological State and Academic Success } \\
\hline $18-22$ & 169 & 2.01 & 0.343 & \multirow{2}{*}{0.08} \\
\hline $23-27$ & 134 & 1.93 & 0.330 & \\
\hline
\end{tabular}

Table 4: A table on the influence of Coronavirus pandemic on students' psychological state and expected future academic success based on gender.

\begin{tabular}{|l|l|l|l|l|}
\hline Gender & N & Mean & Std. Deviation & Mean Diff. \\
\hline Male & 150 & 2.34 & 0.314 & \\
\hline Female & 153 & 2.02 & 0.327 & 0.032 \\
\hline
\end{tabular}

a t-test score of 0.564 . The data indicated by the calculated t-value of 0.564 in respect of students' future academic success which is significant at 0.000 probability level and therefore significant at 0.05 levels of significance. Thus, the null hypothesis that states that Coronavirus pandemic has no influence on students' psychological state and expected future academic success based on their gender is not upheld.

\section{Major findings}

The results presented in this chapter highlighted the following major findings:
1. Coronavirus pandemic causes depression and anxiety to students and has a negative effect on their psychological state and expected future academic success.

2. The study also revealed that the Covid-19 pandemic has an unfavorable effect on economic and sustainable development of Nigeria.

3. Coronavirus pandemic has different effect on the psychological state and expected future success of male and female students.

\section{Discussion of the findings}

Studies related to Coronavirus and students' psychological state: The study Menzies, R.E. \& Menzies, R.G. [4] revealed that COVID-19 has triggered death anxiety and a number of mental health conditions. Such mental health conditions include psychological instability (depression and anxiety). As revealed by the current study. Similarly, The study of Pradhan, Chettri and Maheshwari [8] showed that COVID-19 was positively correlated to neuroticism and death anxiety. In the same way, the study conducted by Xiaoyan, Jiaxiu and Xiaoni [9] found that during the of COVID-19, pandemic, the anxiety and depression level of college students increased significantly, which was also related to multiple factors and it was therefore important to carry out necessary psychological intervention on college students. Jong-Fast [10] observed that death anxiety may be driving a significant amount of 
psychological distress during this pandemic. The study of Ahorsu [11] depict that a lot of Chinese people are passing through psychological distress. Lee [12] found a positive relationship between coronavirus pandemic and anxiety. The study of Rachel E. Menzies and Ross G. Menzies [4] on "Death anxiety in the time of COVID-19: Theoretical explanations and clinical implications which was an experimental study showed that there was anxiety due to the COVID-19 pandemic. This result is in harmony with the finding of this current study which revealed that COVID-19 has a significant effect on the psychological state of students as it has caused them depression and anxiety in no small measure.

Studies related to Coronavirus and students' expected future success: The study of Rüppel, Liersch, and Walter [13] on the influence of psychological well-being on academic success revealed an unexpected negative effect of psychological wellbeing on students' academic success. The study of Mahdy [14] on the impact of COVID-19 pandemic on the academic performance of veterinary medical students revealed that although online education provides an opportunity for self-study. The main challenge online education faces in veterinary medical science is how to give practical lessons. Since most of the subjects are practical; therefore, it is not easy to learn it online. Students think that it is difficult to fulfill the veterinary competencies only with the online education system. The study of Victoria Garza on COVID-19's impact on spring student academic success revealed that about 1,650 students withdrew due to COVID-19, with the vast majority citing issues related to their learning environment [15]. Fewer cited personal or family illness issues related to COVID-19, such as a change in work schedule or dependent care. HyseniDuraku and Hoxha [16] posited that psychological anxiety was predicted by perceived stress, which was predicted by student life. Students found that engaging in online learning enabled them to shift attention away from the pandemic while the emotional support from teachers facilitated for them to cope with this period. However, lack of attention and focus, decreased motivation to attend lessons and study, limited availability of space at home, distraction from family, and having multiple assignments during the lockdown were major challenges facing students' online learning. The International Association of Universities (IAU) [17] which closely monitoring the impacts of COVID-19 on higher education around the world found that more than 1.5 billion students and youth across the planet are affected by school and university closures due to the COVID-19 outbreak. Lamb [18] found that Australian's school students face a decline in their learning and classroom performance as a result of the switch to online learning because of the COVID-19 pandemic. The researchers say the decline will inevitably affect the students' performance at university. Lamb opined that disadvantaged students face the greatest negative impact on their performance. Lamb postulated that many teachers are inexperienced and ill-equipped to cope with a fast transition to online learning. Lamb added that classroom teachers have never had to teach in an online arrangement on the scale now required. Lamb also said that research has shown. Lamb added that fewer than two in every five teachers felt well prepared, or very well prepared, for how they used information technology in their teaching. "There is also an absence of research on how best to deliver classes online to maximize learning," Lamb concluded [19-21].

The COVID-19 pandemic has dwarfed school learning, economic, social and technological development in the recent past. It therefore recommended that the solution to COVID-19 should be found urgently, so that Nigeria, Africa and the world will continue to experience economic and sustainable development. It is only when people are psychologically stable and intellectually balanced that sustainable development can be achieved.

\section{References}

1. World Health Organization (2020) Coronavirus disease (COVID-19): Situation report - 117.

2. Langs (2004) Death anxiety and the emotion-processing mind. Psychoanalytic Psychology 21: 31-53.

3. Sterling, Christopher M (1985) Identity and death anxiety. Department of Psychology, Central Michigan University, Mount Pleasant, MI, 10-11.

4. Menzies RE, Menzies RG (2020) Death anxiety in the time of COVID-19: The theoretical explanations and clinical implications. School of psychology, University of Sydney, Sydney, Australia.

5. Ndukwu EC, Ndukwu EN (2017) Influence of parental expectations on pupils' self-efficacy and academic success. International Academic Journal of Social Sciences and Education 1: 75-88.

6. Ali A (2006) Conducting research in education and social sciences. Tashwa Networks, Enugu.

7. Xinqiao L, Siqing P, Wenjuan $G$ (2019) Changes in undergraduate students' psychological well-being as they experience university life. Int J Environ Res Public Health 16: 2864.

8. Pradhan M, Chettri A, Maheshwari (2020) Fear of death in the shadow of COVID-19: The mediating role of perceived stress in the relationship between neuroticism and death anxiety. Death stud 1: 748-1187.

9. Xiaoyan L, Jiaxiu L, Xiaoni Z (2020) Psychological state of college students during COVID-19 Epidemic. The Lancet Gobal Health.

10. Jong-Fast $M$ (2020) Why are so many baby boomers in denial over the Coronavirus? Vogue Retrieved.

11. Ahorsu DK, Chung-Ying L, Imani V, et al. (2020) The Fear of COVID-19 Scale: development and initial validation. Int J Ment Health Addict 27: 1-9.

12. Lee SA (2020) Coronavirus anxiety scale: A brief mental health screener for COVID-19 related anxiety. Death Stud 44: 393-401.

13. Rüppel F, Liersch S, Walter $U$ (2015) The influence of psychological well-being on academic success. Journal of Public Health 23: 15-24.

14. Mahdy M (2020) The Impact of COVID-19 pandemic on the academic performance of veterinary medical students. Front Vet Sci 7: 594261.

15. Garza V (2020) COVID-19's impact on spring student academic success. Switzerland. MDPI Basel.

16. Hyseni-Duraku Z, Hoxha L (2020) The impact of COVID-19 on higher education: A study of interaction among students' mental health, attitudes toward online learning, study skills, and changes in students' life.

17. International Association of Universities: The Global Voice of Higher Education (2020) COVID-19: Higher Education challenges and responses. International Association of Universities, UNESCO House, 1 rue Miollis, 75732 Paris cedex 15. 
18. Lamb S (2020) COVID-19 - Online leads to student performance decline. Centre for International Research on Education Systems at Victoria University in Melbourne.

19. Cao W, Fang Z, Guoqiang, H, et al. (2020) The psychological impact of the COVID-19 epidemic on college students in China. Psychiatry Res 287: 112934.
20. WHO (2020) WHO Director-General's opening remarks at the media briefing on COVID-19 - 11 March 2020.

21. Wu Z, McGoogan JM (2020) Characteristics of and important lessons from the coronavirus disease 2019 (COVID-19) outbreak in China: Summary of a report of 72,314 cases from the Chinese Center for Disease Control and Prevention. JAMA 323: 1239-1242. 